\title{
RANCANGAN BAJU PANAHAN YANG ERGONOMIS PADA PLANTERS ARCHERY CLUB
}

\author{
Oleh \\ Syamsul Gultom ${ }^{1}$, Arif Maulana ${ }^{1}$ \\ ${ }^{1}$ Fakutas Imu Keolahragaan, Universitas Negeri Medan \\ Email: arif.maaulaana@gmail.com
}

\begin{abstract}
Abstrak
Tujuan penelitian ini adalah untuk menghasilkan suatu produk pakaian yang telah dirancang khusus untuk atlet Panahan dengan konsep ergonomi yang menghasilkan pakaian yang nyaman dan efektif sehingga mempermudah atlet panahan dalam berlatih maupun pertandingan. Penelitian ini dilakukan di planters archery club tepatnya di Sekolah Tinggi Ilmu Pertanian Agrobisnis Perkebunan (STIPAP), pengambilan data dimulai dari mulai Juli-Oktober 2018. Jumlah sampel pada penelitian ini berjumlah 6 orang. Peneltian ini merupakan jenis penelitian pengembangan atau Research and Development (R\&D). Metode yang digunakan dalam penelitian ini adalah meliputi beberapa tahan yaitu : (1) tahap analisis kebutuhan, (2) tahap pengembangan produk, (3) tahap validasi produk, (4) tahap ujicoba produk. Dari/hasil validasi ahli/pada pengembangan produk pakaian dinyatakan bahwa pakaian layak digunakan pada atlet Panahan untuk melakukan olahraga Panahan yaitu dengan skor 83 kategori sangat baik dari ahli Panahan dan skor 88 kategori sangat baik dari ahli tata busana. Maka rancangan yang sudah dirancang layak digunakan.
\end{abstract}

Kata kunci : Pakaian Ergonomis, Atlet Panahan, R\&D, Planters Archery Club

\section{A. PENDAHULUAN}

Olahraga adalah proses sistematik yang terdiri atas setiap kegiatan dan usaha yang dapat membantu perkembangan atau membina potensi-potensi jasmaniah dan rohaniah seseorang sebagai perorangan atupun anggota masyarakat. Olahraga dapat berupa permainan, pertandingan serta prestasi puncak didalam pembentukan manusia yang memiliki idiologi yang seutuhnya dan berkualitas yang didasarkan pada dasar negara dan pancasila (Pelana dan Nadya 2017:1).

Olahraga yang bersifat kelompok tergabung dari banyak individu membentuk suatu tim dan diharapkan saling bekerjasama dalam membangun suatu strategi sedangkan olahraga yang bersifat individu tidak melibatkan kerjasama antar satu tim. Dalam olahraga yang bersifat individu tetap memerlukan motivasi, baik dari pelatih, official maupun orang yang terlibat dalam olahraga, karena dalam olahraga tetap semua saling membutuhkan, saling berhubungan, saling berinteraksi dan serta saling 
mempengaruhi baik dalam latihan maupun kompetisi. Banyak cabang olahraga prestasi yang melibatkan kemampuan individu, misalnya pencak silat, golf dan panahan.

Panahan adalah semacam senjata yang berupa barang panjang, tajam pada ujungnya diberi bulu pada pangkalnya yang dilepas dengan busur, sedangkan memanah adalah melepaskan anak panah terhadap target (Yudik Prasetio,2011 dalam Julian). Olahraga panahan membutuhkan keahlian atau skill tersendiri. Dalam pertandingan memanah, setiap pemain harus mampu melepaskan anak panahnya tepat mengenai sasaran yang telah ditentukan. Seorang yang gemar atau merupakan ahli dalam memanah disebut juga sebagai pemanah. Menurut Wayan Artanayasa (2014:1).

Didalam olahraga panahan memerlukan konsentrasi yang baik saat memanah, dengan posisi siap atau stance posisi kaki dibuka berjarak kurang lebih selebar bahu dengan posisi tubuh tegak, titik berat badan bertumpu di kedua kaki secara seimbang, posisi kepala menoleh ke sasaran, pada posisi set-up tali busur berada pada diposisi setengah lengan kiri dan posisi according tangan penarik berada dibawah dagu dengan tali menyentuh hidung dan bibir lakukan penggetaran lalu melepas dan setelah itu colling down.

Baju yang sering dipakai atlet panahan sampai saat ini biasanya baju kaos polos layaknya baju yang digunakan road (jalan-jalan). baju yang ergonomis sangat dibutuhkan untuk berlangsungnya kegiatan latihan atlet, dengan menggabungkan alat pelindung Arm Guard dan Chest Guard kepada baju yang akan dirancang agar atlet panahan tersebut dapat melakukan kegiatan latihan atau pertandingan dengan nyaman dan tidak tergangu dengan baju yang biasa-biasa saja. Ditambah dengan terlalu susah menggunakan alat pengaman panahan seperti Arm Guard dan Chest Guard dengan mengancing / memperketat dengan bantuan seseorang .

Istilah ergonomi berasal dari bahasa Latin yaitu ergon (kerja) dan nomos (hukum alam) dan dapat didefinisikan sebagai studi tentang aspek-aspek manusia dalam lingkungan kerjanya yang ditinjau secara anatomi, fisiologi, psikologi, engineering, manajemen dan desain perancangan. Ergonomi berkenaan pula dengan optimasi, efisiensi, kesehatan, keselamatan dan kenyamanan manusia di tempat kerja, di rumah dan tempat rekreasi. Ergonomi berasal dari bahas yunani, yaitu ergos (bekerja) dan Nomos (Ilmu pengetahuan). Ergonomi merupakan ilmu yang mempelajari kemampuan manusia dalam berinteraksi dengan lingkungan fisiknya. Ergonomi yaitu "Suatu cabang 
ilmu yang sistematis untuk memanfaatkan informasi-informasi mengenai sifat, kemampuan dan keterbatasan manusia untuk merancang sistem kerja sehingga orang dapat hidup dan bekerja pada sistem itu dengan baik, yaitu mencapai tujuan yang diinginkan melalui pekerjaan itu, dengan efektif, aman dan nyaman" (Sutalaksana, 2004 dalam Rosnani Ginting).

Menurut Thomas Reilly, Dengan pengembangan Sport Ergonomic Model karena dari Sport Ergonomic Model turun nya dari Equipment salah satu nya kebutuhan berpakaian yang berdasarkan kebutuhan dari atlet. Macam-macam kebutuhan pakaian yang dapat mendukung meningkatnya performance atlet. Kebutuhan ini salah satu penunjang untuk keberhasilan atlet dan dapat digunakan untuk atlet-atlet Panahan lain yang berminat memakainya.

Menurut Giriwijoyo (2012) olahraga kesehatan mengacu pada olahraga dengan padat gerak tidak ada waktu terbuang dengan sia-sia, bebas stres, singkat (cukup 10-30 menit tampa henti), misalnya (dilakukan oleh banyak orang, sebagai ajang interaksi saling menghargai, saling mengasihi dan saling-mengingatkan), mudah (gerakan tidak sulit, dapat dilakukan oleh semua orang tanpa harus menggunakan teknik tinggi), murah, meriah (bebas dari stress, non kompetitif), dan fisiologis (bermanfaat dan aman, intensitas dalam batas sesuai kemampuan masing-masing, yaitu antara $65-70 \%$ dari denyut nadi maksimal, atau dikatakan intensitasnya sub maksimal), dilakukan 3-5 kali dalam satu minggu, diselingi hari istirahat. Contohnya: senam aerobik dilakukan selama 35 menit non stop, kecepatan gerakan mampu merangsang jantung berdenyut sebanyak 140 kali/menit. Jadi volumenya 35 menit, dan intensitasnya berupa denyut jantung/nadi sebanyak $140 \mathrm{kali} /$ menit. Contoh lainnya adalah joging lari mengelilingi stadion sebanyak 6 kali keliling, waktu yang digunakan untuk menyelesaikan kegiatannya adalah 12 menit.

Menurut Nurmianto Eko (2004) dalam Petrus W dan Rina S antropometri adalah kumpulan data numerik yang berhubungan dengan karakteristik tubuh manusia ukuran, bentuk, dan kekuatan serta penerapan dari data terebut untuk penanganan masalah desain. Menurut Wignjosoebroto(2000) dalam Firman S dan Arief R antropometri adalah sebuah studi yang berkaitan dengan pengukuran dimensi tubuh manusia.Data antropometri digunakan untuk berbagai keperluan seperti perancangan lingkungan kerja (workplaces), fasilitas kerja, dll agar diperoleh ukuran-ukuran yang sesuai dan layak 
dengan dimensi ukuran anggota tubuh manusia yang akan menggunakannya. Hal ini dilakukan agar tercapai suatu kondisi yang enak, nyaman, aman, dan sehat bagi manusia dan tentunya juga dapat menciptakan kondisi kerja yang efisien dengan hasil yang efektif atau dengan kata lain adalah untuk mencapai keadaan yang ergonomis.

Didalam sebuah industri garmen atau industri pakaian jadi, kain merupakan salah satu bahan yang tidak dapat diabaikan, sebab kain merupakan salah satu bahan dasar (raw material) dalam produksi garmen. Karena merupakan bahan pokok, maka tinggi rendahnya kualitas kain akan sangat berpengaruh terhadap tinggi rendahnya kualitas produk garmen yang dihasilkan. Dalam hal ini, mutu/kualitas garmen sangat tergantung pada mutu/kualitas kain, sehingga mutu garmen (pakaian jadi) selama proses produksi harus diawasi dan "dikendalikan" agar "tetap" dalam batas toleransi standar mutu yang diminta oleh konsumen (Reda Rizal, 2006 dalam Widihastuti).

Panahan ialah Olahraga yang mampu melatih kekuatan, ketahanan, fokus, koordinasi tangan dan mata, keseimbangan, meningkatkan fleksebilitas tangan dan jari, meningkatkan kesabaran dan membangun kepercayaan diri. Dalam melakukan olahraga panahan banyak aktivitas gerak yang dilakukan dengan tarikan dan semacamnya. Dengan menggunakan baju yang biasa-biasa atau baju yang layaknya digunakan jalanjalan (road) atlet panahan mengalami aktifitas gerak terbatas, maka dari itu peneliti ingin merancang baju panahan yang ergonomis dengan sport ergonomic model yaitu menanyakan kebutuhan berpakaian berdasarkan kebutuhan atlet, untuk menjadikan baju panahan nyaman dan efektif.

\section{B. METODOLOGI PENELITIAN}

Penelitian ini dilaksanakan di Sekolah Tinggi Ilmu Pertanian Agrobisnis Perkebunan (STIPAP) JL: Willem Iskandar, Kenangan Baru, Percut Sei Tuan, Kota Medan, Sumatra Utara. Populasi dalam penelitian ini adalah atlit Panahan yang masih aktif di Planters Archery Club yang berjumlah 6 orang. Sampel dalam penelitian ini adalah atlit Panahan Planters Archery Club. Kategori anak-anak, remaja dan orang dewasa. Teknik pengambilan sampel dengan cara purposive sampling, menurut Sugiyono purposive sampling yaitu atlet dipilih dengan pertimbangan dan tujuan tertentu. Berdasarkan kriteria tersebut maka jumlah sampel dalam penelitian ini adalah 6 orang atlit. 
Metode yang digunakan dalam penelitian ini adalah meliputi beberapa tahapan yaitu: (1) tahap analisis kebutuhan, (2) tahap pengembangan produk (3) tahap validasi produk (4) tahap uji coba I produk (5) tahap revisi produk (6) tahap uji coba II produk. Desain yang digunakan dalam penelitian ini meliputi 6 langkah utama, yaitu Analisis kebutuhan, Perancangan produk, Validasi produk, Uji coba I produk, Tahap Revisi, dan Uji coba II produk. Setiap langkah utama terdapat beberapa langkah di dalamnya. Variabel dalam penelitian ini adalah rancangan baju panahan yang ergonomis untuk aktifitas panahan. Baju panahan yang ergonomis adalah baju yang dirancang dengan menggunakan metode ergonomi Follow-up, dengan evaluasi yang subyektif atau obyektif, subyektif misalnya dengan menanyakan kenyamanan menggunakan angket dan lembar observasi. Menurut Tarwaka, dkk (2004), Teknik analisis data yang digunakan dalam penelitian ini menggunakan analisis data kualitatif. Diagnosis, Treatment, Follow-up.

\section{HASIL DAN PEMBAHASAN PENELITIAN}

\section{HASIL PENELITIAN}

Tabel 1

Hasil Validasi Ahli Desain

\begin{tabular}{|c|c|c|c|c|}
\hline NO & ASPEK & $\begin{array}{l}\text { KRITERIA DAN INDIKATOR } \\
\text { PENILAIAN }\end{array}$ & BOBOT & NILAI \\
\hline (1) & (2) & (3) & (4) & (5) \\
\hline \multirow[b]{2}{*}{1} & \multirow[b]{2}{*}{$\begin{array}{c}\text { Aspek } \\
\text { Orisinalitas }\end{array}$} & Merupakan hasil karya peneliti & 10 & 9 \\
\hline & & $\begin{array}{l}\text { Memiliki fitur pembeda dibandingkan } \\
\text { dengan teknologi olahraga yang serupa } \\
\text { dan sudah ada (orisinalitas) }\end{array}$ & 10 & 8 \\
\hline 2 & $\begin{array}{l}\text { Aspek } \\
\text { Keunggulan } \\
\text { Inovasi }\end{array}$ & $\begin{array}{l}\text { Memiliki keunggulan dalam dalam hal } \\
\text { kualitas karya inovatif, bahan, } \\
\text { pengoperasian, dan pemeliharaan. }\end{array}$ & 10 & 8 \\
\hline 3 & $\begin{array}{c}\text { Aspek } \\
\text { Kebermanfaa } \\
\tan \end{array}$ & $\begin{array}{l}\text { Memiliki daya guna yang tinggi bagi } \\
\text { khalayak luas dalam mendukung tes dan } \\
\text { pengukuran. }\end{array}$ & 20 & 18 \\
\hline
\end{tabular}




\begin{tabular}{|c|c|c|c|c|}
\hline \multirow[t]{2}{*}{4} & \multirow{2}{*}{$\begin{array}{l}\text { Aspek } \\
\text { Ekonomi }\end{array}$} & $\begin{array}{l}\text { Memiliki dampak positif dari penerapan } \\
\text { teknologi dan industrialisasi } \\
\text { pengembangan model baju panahan. }\end{array}$ & 10 & 9 \\
\hline & & $\begin{array}{l}\text { Memiliki potensi komersialisasi dan } \\
\text { keterjangkauan pasar }\end{array}$ & 10 & 8 \\
\hline 5 & $\begin{array}{c}\text { Aspek } \\
\text { Keamanan }\end{array}$ & $\begin{array}{l}\text { Memiliki tingkat keamanan yang baik } \\
\text { selama digunakan tes dan pengukuran }\end{array}$ & 10 & 9 \\
\hline 6 & $\begin{array}{c}\text { Aspek } \\
\text { Kenyamanan }\end{array}$ & $\begin{array}{l}\text { Memiliki tingkat kenyamanan } \\
\text { (partisipan dapat melakukan sendiri } \\
\text { tanpa bantuan orang lain) }\end{array}$ & 10 & 10 \\
\hline 7 & $\begin{array}{c}\text { Aspek } \\
\text { Kelengkapan } \\
\text { Data } \\
\text { Pendukung }\end{array}$ & $\begin{array}{l}\text { Memiliki Deskripsi tentang manual } \\
\text { penggunaan pakaian yang ergonomi }\end{array}$ & 10 & 9 \\
\hline & & Jumlah Sko & D & 88 \\
\hline NO & ASPEK & $\begin{array}{l}\text { KRITERIA DAN INDIKATOR } \\
\text { PENILAIAN }\end{array}$ & BOBOT & NILAI \\
\hline (1) & (2) & (3) & (4) & (5) \\
\hline & & Merupakan hasil karya peneliti & 10 & 9 \\
\hline 1 & $\begin{array}{c}\text { Aspek } \\
\text { Orisinalitas }\end{array}$ & $\begin{array}{l}\text { Memiliki fitur pembeda dibandingkan } \\
\text { dengan teknologi olahraga yang serupa } \\
\text { dan sudah ada (orisinalitas) }\end{array}$ & 10 & 9 \\
\hline 2 & $\begin{array}{l}\text { Aspek } \\
\text { Keunggulan } \\
\text { Inovasi }\end{array}$ & $\begin{array}{l}\text { Memiliki keunggulan dalam dalam hal } \\
\text { kualitas karya inovatif, bahan, } \\
\text { pengoperasian, dan pemeliharaan. }\end{array}$ & 10 & 7 \\
\hline 3 & $\begin{array}{c}\text { Aspek } \\
\text { Kebermanfaa } \\
\quad \tan \end{array}$ & $\begin{array}{l}\text { Memiliki daya guna yang tinggi bagi } \\
\text { khalayak luas dalam mendukung tes dan } \\
\text { pengukuran. }\end{array}$ & 20 & 19 \\
\hline
\end{tabular}




\begin{tabular}{|c|c|c|c|c|}
\hline \multirow[t]{2}{*}{4} & \multirow{2}{*}{$\begin{array}{l}\text { Aspek } \\
\text { Ekonomi }\end{array}$} & $\begin{array}{l}\text { Memiliki dampak positif dari penerapan } \\
\text { teknologi dan industrialisasi } \\
\text { pengembangan model baju panahan. }\end{array}$ & 10 & 8 \\
\hline & & $\begin{array}{l}\text { Memiliki potensi komersialisasi dan } \\
\text { keterjangkauan pasar }\end{array}$ & 10 & 7 \\
\hline 5 & $\begin{array}{c}\text { Aspek } \\
\text { Keamanan }\end{array}$ & $\begin{array}{l}\text { Memiliki tingkat keamanan yang baik } \\
\text { selama digunakan tes dan pengukuran }\end{array}$ & 10 & 8 \\
\hline 6 & $\begin{array}{c}\text { Aspek } \\
\text { Kenyamanan }\end{array}$ & $\begin{array}{l}\text { Memiliki tingkat kenyamanan } \\
\text { (partisipan dapat melakukan sendiri } \\
\text { tanpa bantuan orang lain) }\end{array}$ & 10 & 8 \\
\hline 7 & $\begin{array}{c}\text { Aspek } \\
\text { Kelengkapan } \\
\text { Data } \\
\text { Pendukung }\end{array}$ & $\begin{array}{l}\text { Memiliki Deskripsi tentang manual } \\
\text { penggunaan pakaian yang ergonomi }\end{array}$ & 10 & 8 \\
\hline & & Jumlah Skor & $\square$ & 83 \\
\hline
\end{tabular}

Berdasarkan hasil validasi ahli desain (Dewi Herawaty) menunjukkan hasil jumlah skor-sebesar 88 dengan kategori skala "baik sekali" Dan hasil validasi ahli panahan ( Yose Andre Sinohaji ) menunjukkan hasil jumlah skor sebesar 83 dengan kategori skala "baik sekali".

Jawaban Atlet Pada desain pertama rancangan baju panahan yang ergonomis dengan busa yellow berbentuk persegi dibagian dada sebagai pengganti chest guard dan kulit sintetis pada lengan bawah bagian dalam sebagian besar responden menyatakan sudah nyaman dan efektif dalam menggunakan pakaian tersebut.

Selanjutnya ujicoba yang kedua sebanyak 6 orang. Desain baju yang sebelumnya berbentuk persegi pada chest guard kini direvisi sesuai permintaan atlet yaitu busa pada chest guard dilebarkan sampai dengan arah bahu sesuai ukuran dada pada atlet dan dibagian puncak lengan diberikan tambahan bahan sehingga menyamankan dalam hal penarikan.

\section{PEMBAHASAN PENELITIAN}

Hasil penelitian dan pengembangan ini adalah produk baju yang ergonomis pada atlet panahan Planters Archery Club. Baju hasil rancangan peneliti berdasarkan kebutuhan atlet dapat dilihat pada gambar dibawah ini 


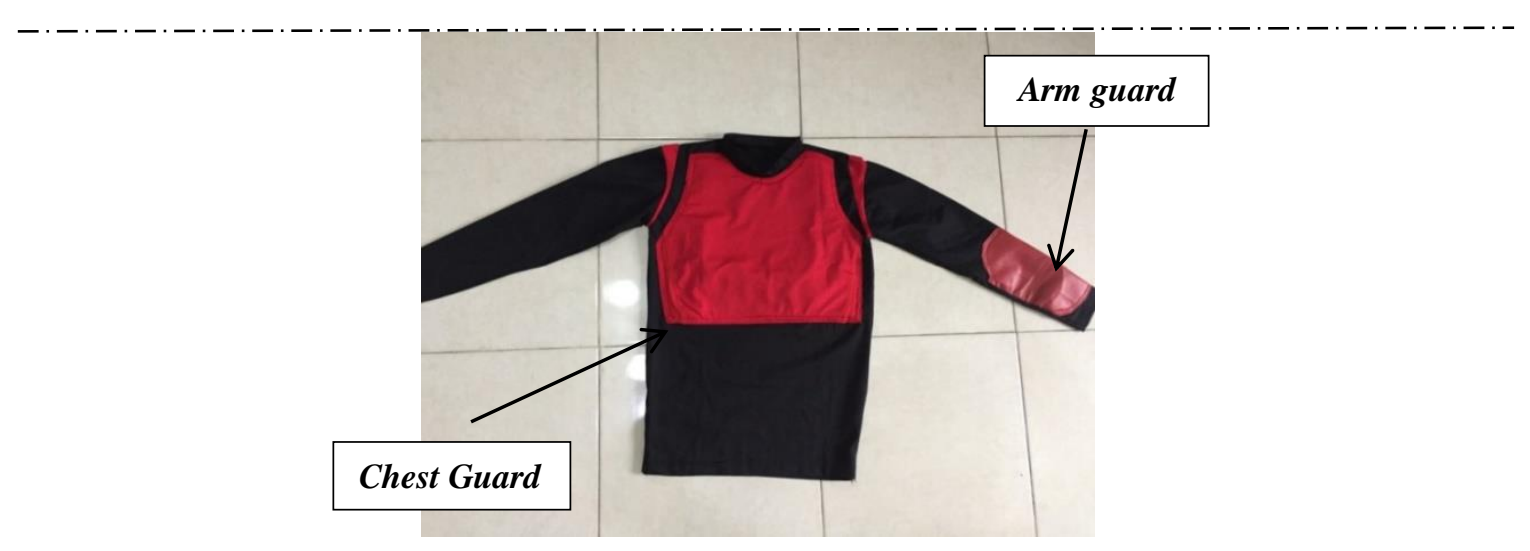

Gambar 1. Baju Yang Dirancang peneliti

Dari gambar yang sudah ditandai pada tanda panah tersebut adalah Chest Guard dan Arm Guard dimana Chest Guard menggunakan busa untuk melindungi dada pada saat pelepasan panah sehingga tidak menghambat jalannya panah. Sedangkan Arm Guard menggunakan bahan kulit, Arm Guard ialah pelindung lengan berfungsi untuk melindungi tangan pemegang busur dari tali busur saat melepas anak panah. Maka model baju ergonomis tersebut dirancang hanya untuk cabang olahraga Panahan.

$90 \%$ Responden menyatakan baju panahan yang dirancang sudah efektif dan nyaman untuk digunakan pada olahraga panahan. Hal ini menjadi masukan bagi peneliti untuk mengembangkan pakaian sesuai kebutuhan di masa yang akan datang. Dan menjadi reverensi selanjutnya untuk penelitian yang akan datang.

Baju panahan yang telah di rancang khusus membantu mempermudah atlet panahan pada saat mereka latihan maupun bertanding. Baju yang telah dikembangkan membantu atlet untuk aktif dan semangat dalam melakukan gerakan-gerakan yang fleksibel dan juga membuat aman dan nyaman atlet selama menggunakannya.

\section{KESIMPULAN}

Berdasarkan hasil penelitian dan pembahasan rancangan baju panahan yang ergonomis pada Planters Archery Club di Lembaga Pendidikan Perkebunan (LPP) dan Sekolah Tinggi Ilmu Pertanian Agrobisnis Perkebunan (STIPAP), dapat diambil kesimpulan bahwa hasil rancangan baju panahan yang ergonomis pada Planters Archery Club sangat baik untuk digunakan. 


\section{Daftar Pustaka}

Artanayasa, Wayan , (2014). Panahan. Yogyakarta: Graha Ilmu

Firman, Arief Rahman. (2009). Perancangan Sistem Pengukuran Antropometri Badan dan Pembuatan Pola dalam Industri Konveksi dengan Menggunkaan Image Processing. Surabaya: Jurnal digilib Institut Teknologi Sepuluh Nopember (ITS).

Ginting, Rosnani. (2010). Perancangan Produk. Yogyakarta: Graha Ilmu.

Giriwijoyo, Santosa dan Dikdik Zafar Sidik. (2012). Ilmu Faal Olahraga (Fisiologi Olahraga). Bandung: Remaja Rosdakarya.

Julian, Dewantara. (2016). Identifikasi Macam, Jenis, dan Lokasi Cedera Olahraga Atlet Panahan Kontingen-Klaten. Yogyakarta: Jurnal Universitas Negeri Yogyakarta. vol 5. no 1, hal 1-2.

Nurmianto, Eko. (2004). Ergonomi Konsep Dasar dan Aplikasinya Edisi Kedua. Surabaya: Guna Widya.

Pelana, Ramdan dan Oktafiranda, Nadya, (2017). Teknik Dasar Olahraga Panahan. Depok: PT RajaGrafindo Persada

Reilly, Thomas. (2010). Ergonomics. Enhancing Performance and Improving Safety. Human Kinetios United States Of America.

Sugiyono. (2016). Metode Penelitian Kuantitatif, Kualitatif, dan R\&D. Bandung: Alfabeta.

Tarwaka, Solichul dan Lilik Sudiajeng. V(2004). Ergonomi untuk Kesehatan, Keselamatan Kerja dan Produktivitas. Surakarta: UNIBA Press.

Widihastuti. (2006). Kendali Mutu Kain dalam Industri Garmen Modern. Yogyakarta: Jurnal Teknik Busana. 